\title{
Association of transforming growth factor- $\beta 1$ gene polymorphisms with a hepatocellular carcinoma risk in patients with chronic hepatitis $B$ virus infection
}

\author{
Yoon Jun Kim, Hyo-Suk Lee ${ }^{1,3}$, Jong Pil $\mathrm{Im}^{1}$, \\ Byung-Hoon Min ${ }^{1}$, Hyun-Dae Kim ${ }^{1}$, \\ Ji Bong Jeong', Jung-Hwan Yoon', \\ Chung Yong Kim ${ }^{1}$, Myung Soo Kim², \\ Jun Yeon Kim², Ji Hyun Jung', \\ Lyoung Hyo Kim², Byung Lae Park \\ and Hyoung Doo Shin ${ }^{2}$ \\ 'Department of Internal Medicine \\ and Liver Research Institute \\ Seoul National University College of Medicine \\ Seoul 110-744, Korea \\ ${ }^{2}$ Department of Genetic Epidemiology \\ SNP Genetics, Inc., Seoul, Korea \\ ${ }^{3}$ Corresponding author: Tel, 82-2-745-7557; \\ Fax, 82-2-744-8243; E-mail, hsleemd@snu.ac.kr
}

Accepted 20 May 2003

Abbreviations: anti-HBc, antibody to hepatitis B core antigen; anti-HCV, antibody to hepatitis $C$ virus antigen; anti-HIV, antibody to human immunodeficiency virus antigen; HBV, hepatitis B virus; HCC, hepatocellular carcinoma; SBE, single base extension; SNP, single nucleotide polymorphism; TGF- $\beta$, transforming growth Factor- $\beta$

\begin{abstract}
Transforming growth factor- $\beta 1$ (TGF- $\beta 1$ ) can act as both a tumor suppressor and a stimulator of tumor progression. We have examined the relationship between polymorphisms of the TGF- $\beta 1$ gene and the risk of hepatocellular carcinoma (HCC) in patients with chronic hepatitis B virus (HBV) infection. A total of 1,237 Korean subjects were prospectively enrolled; 1,046 patients with chronic HBV infection and 191 healthy controls with no evidence of recent or remote HBV infection. The patients were divided into two groups: those without $(n=809)$ and those with HCC $(n=237)$. Single nucleotide polymorphisms (SNPs) of TGF- $\beta 1$ were searched for and genotyped using the single base extension method. In Korean subjects, only two SNPs were found among the seven known polymorphisms of TGF- $\beta 1$, at position -509 and in codon 10. The risk of HCC was significantly lower
\end{abstract}

in patients with the $T / T$ or $C / T$ genotypes than in those with the $\mathrm{C} / \mathrm{C}$ genotypes at position -509 ( $P$ $<0.02$ ), and also lower among those with the Pro/Pro or Leu/Pro genotypes than in those with the Leu/Leu genotypes in codon $10(P<0.007)$. Haplotype analysis revealed that the possession of [-509C > T; L10P] conferred a decreased likelihood of HCC $(\mathrm{OR}=0.74 ; 95 \% \mathrm{Cl}, 0.59-0.93 ; P=$ 0.008 ). In conclusion, the presence of the TGF- $\beta 1$ $-509 \mathrm{C}>\mathrm{T}$ promoter or of the L10P polymorphism, and the combination of both [-509C $>\mathrm{T}$; L10P] as a haplotype were strongly associated with a reduced risk of HCC in patients with chronic HBV infection.

Keywords: chronic hepatitis; HBV; genetic susceptibility; hepatocellular carcinoma; single nucleotide polymorphism; transforming growth factor- $\beta 1$

\section{Introduction}

Chronic hepatitis B virus (HBV) infection is a global public health problem as this virus is known to infect more than 350 million people worldwide and is one of the major risk factors of hepatocellular carcinoma (HCC) (Purcell, 1993). HCC is etiologically associated with HBV in $80 \%$ of cases ( $\mathrm{Yu}$ et al., 2000a), and is the dominant cause of death among HBV carriers, with a lifetime risk of $27 \%$ for males and $4 \%$ for females (Dickinson et al., 2002). Among patients with chronic HBV infection, family history is a known risk factor for the development of HCC (Yu et al., 2000b); therefore, genetic factors are likely to modify the risk of HCC. However, the genetic factors that determine progression to HCC remain unknown.

Single nucleotide polymorphisms (SNPs) has emerged as one of the important tools for tracking down the genes responsible for conferring susceptibility to common diseases, such as heart disease and cancer. Among those genes that may be involved in oncogenesis, transforming growth factor- $\beta$ (TGF- $\beta$ ) has been identified as both a tumor suppressor during the early stages of tumorigenesis and a significant stimulator of tumor growth, invasion and metastasis during tumor progression (Cui et al., 1996). In most epithelial and endothelial cells, TGF- $\beta$ causes arrest of the cell cycle, and potently suppresses the prolif- 
eration of hepatocytes (Wollenberg et al., 1987). A recent case-control study showed that a polymorphism in the type I receptor for TGF- $\beta$ that leads to decreased biological activity may be associated with increased risk of colon cancer (Pasche et al., 1999). Changes in the expression of one of the TGF- $\beta$ ligands, TGF$\beta 1$, have also been implicated in oncogenesis in transgenic mice; deletion of one copy of the TGF- $\beta 1$ gene leads to increased cell turnover and susceptibility to liver and lung tumors when induced by carcinogens (Tang et al., 1998). The production of TGF- $\beta 1$ is under genetic control (Awad et al., 1998; El-Gamel et al., 1999; Grainger et al., 1999), and seven polymorphisms have been described in the coding and promoter region of the TGF- $\beta 1$ gene (Cambien et al., 1996). The present study was to investigate the relationships between the known seven SNPS of the TGF- $\beta 1$ gene and the risk of HCC occurrence in patients with chronic HBV infection in Korea.

\section{Materials and Methods}

\section{Subjects}

A total of 1,237 Korean subjects were prospectively enrolled; 1,046 patients with chronic HBV infection from a liver unit and $191 \mathrm{lgG}$ anti-HBc negative healthy subjects from the Center for Health Promotion at Seoul National University Hospital between January 2001 and August 2001. Among the 1,046 HBV infected patients, 791 were male and 255 female. Patient ages ranged from 20 to 75 years with a mean age of $50.4(S D=10.4)$ years. Patients with chronic HBV infection were further divided into 2 groups: without $(n=809)$ and with HCC $(n=237)$ according to the absence or presence of concurrent HCC. HCC was diagnosed as described (Bruix et al., 2001). Among patients with chronic HBV infection, patients with $\mathrm{HCC}$ were older than those without HCC (Table 1). The inclusion criteria for chronic HBV infection were repeated seropositivity for hepatitis $B$ surface antigen by ELISA (Enzygnost ${ }^{(\mathbb{R})}$ HBsAg 5.0; Dade Behring, Marburg, Germany) for a period of at least 6 months. Patients who were positive for anti-HCV or anti-HIV by

Table 1. The characteristics of patients with chronic HBV infection.

\begin{tabular}{lcccc}
\hline \multirow{2}{*}{ Group } & \multicolumn{3}{c}{ No. of patients } & \multirow{2}{*}{$\begin{array}{c}\text { Age } \\
\text { (Mean } \pm \text { SD) }\end{array}$} \\
\cline { 2 - 4 } & Total & Males & Females & \\
\hline Without HCC & 809 & 598 & 211 & $49.0 \pm 10.5$ \\
With HCC & 237 & 193 & 44 & $55.6 \pm 8.8$ \\
\hline Total & 1,046 & 791 & 255 & $50.4 \pm 10.4$ \\
\hline
\end{tabular}

ELISA ( $\mathrm{HCV}^{(\mathrm{R})}$ 3.2; Dong-A Pharmaceutical Co., Seoul, Korea, GENEDIA ${ }^{(\mathrm{R})}$; Greencross Life Science Corp., Yongin-shi, Korea, respectively) and whose average alcohol consumption assessed by interview was $\geq 10$ $\mathrm{g} /$ day were excluded. The consumption and types of alcohol drinking were asked and the alcohol content of each drink was calculated. Weekly alcohol intake was converted into alcohol grams/day. The patients who have any other types of liver disease such as autoimmune hepatitis, toxic hepatitis, primary biliary cirrhosis or Budd-Chiari syndrome were also excluded. We also excluded subjects who had a previous history of immunosuppression or anti-viral treatment.

Informed consent was obtained from each patient, and the Institutional Review Board of Seoul National

Table 2. Sequences of amplifying primers used for direct sequencing of TGF- $\beta 1$ gene.

\begin{tabular}{lc}
\hline Primer & \multicolumn{1}{c}{ Sequence } \\
\hline Promoter-1 (forward) & 5'-ATGCCAGGTGGAAGGTGAT-3' \\
Promoter-1 (reverse) & 5'-TGCCAACTGTTCTCGCCAAC-3' \\
& \\
Promoter-2 (forward) & 5'-CTTGCAGGCTATGGATTTTGC-3' \\
Promoter-2 (reverse) & 5'-ATCCAGATGCGCTGTGGCTT-3' \\
& \\
Promoter-3 (forward) & 5'-GAGGCCCCATGTTGACAGA-3' \\
Promoter-3 (reverse) & 5'-CCCAGCGGCAACGGAAAAGT-3' \\
& \\
5' UTR (forward) & 5'-GAGGAAGGAGTCGCCGAGGA-3' \\
5' UTR (reverse) & 5'-CGATAGTCTTGCAGGTGGATAG-3' \\
& \\
Exon1 (forward) & 5'-CCCACCACACCAGCCCTGTTC-3' \\
Exon1 (reverse) & 5'-GTGTCCTCTTCCTCCAGCCAGT-3' \\
& \\
Exon2 (forward) & 5'-GGTATCAGAGACTGACTCCA-3' \\
Exon2 (reverse) & 5'-AGTTCTAGGATTGTATGGTTTG-3' \\
& \\
Exon3 (forward) & 5'-ACACCTTCGGCTGAGCTGT-3' \\
Exon3 (reverse) & 5'-AGATTAGCCAATCACTCAGGT-3' \\
Exon4/5 (forward) & 5'-TGCAGTGAGAGGGCAGAGT-3' \\
Exon4/5 (reverse) & 5'-GCTAAAGGAGACAGATGCTC-3' \\
\hline & \\
\hline
\end{tabular}


Table 3. Sequences of amplifying and extension primers for TGF- $\beta 1$ single nucleotide polymorphism genotyping by the single base extension method.

\begin{tabular}{|c|c|c|}
\hline & Primer & Sequence \\
\hline TGF- $\beta 1$ & $-800 \mathrm{G}>\mathrm{A}($ forward $)$ & 5'-CTTGCAGGCTATGGATTTTGC-3' \\
\hline TGF- $\beta 1$ & $-800 \mathrm{G}>\mathrm{A}$ (reverse) & 5'-ATCCAGATGCGCTGTGGCTT-3' \\
\hline TGF- $\beta 1$ & $-800 \mathrm{G}>\mathrm{A}$ (extension) & 5'-TGAGGGACTCTGCCTCCAAC-3' \\
\hline TGF- $\beta 1$ & $-509 \mathrm{C}>\mathrm{T}$ (forward) & 5'-CTTGCAGGCTATGGATTTTGC-3' \\
\hline TGF- $\beta 1$ & $-509 \mathrm{C}>\mathrm{T}($ reverse) & 5'-ATCCAGATGCGCTGTGGCTT-3' \\
\hline TGF- $\beta 1$ & $-509 \mathrm{C}>\mathrm{T}$ (extension) & 5'-TAATCAATGATGATGGGCAACAGGACACCTGA-3' \\
\hline TGF- $\beta 1$ & L.10P (forward) & 5'-CCCACCACACCAGCCCTGTTC-3' \\
\hline TGF- $\beta 1$ & L10P (reverse) & 5'-GTGTCCTCTTCCTCCAGCCAGT-3' \\
\hline TGF- $\beta 1$ & L10P (extension) & 5'-ACAGCAGCGGTAGCAGCAGC-3' \\
\hline TGF- $\beta 1$ & R25P (forward) & 5'-CCCACCACACCAGCCCTGTTC-3' \\
\hline TGF- $\beta 1$ & R25P (reverse) & 5'-GTGTCCTCTTCCTCCAGCCAGT-3' \\
\hline TGF- $\beta 1$ & R25P (extension) & 5'-CATGATTATAATCAATGATGATGTGGCTACTGGTGCTGACGCCTGGCC-3' \\
\hline TGF- $\beta 1$ & T2631 (forward) & 5'-TGCAGTGAGAGGGCAGAGT-3' \\
\hline TGF- $\beta 1$ & T2631 (reverse) & 5'-GCTAAAGGAGACAGATGCTC-3' \\
\hline TGF- $\beta 1$ & T263I (extension) & 5'-ATCAATGATGATCCGGCCTTTCCTGCTTCTCATGGCCA-3' \\
\hline
\end{tabular}

University Hospital approved the study protocol.

\section{Identification and validation of the SNPs of the TGF- $\beta 1$ gene in the Korean population}

Polymorphisms of TGF- $\beta 1$ were identified in 24 unrelated Korean individuals by direct sequencing of the 7 exons and the promoter region. Genomic DNA was prepared from each blood sample using a QIA amp blood kit (QIAGEN Inc., Valencia, CA). The primers used for direct sequencing are listed in Table 2. To clean up the PCR products, we used a Montage PCR96 Cleanup Kit (Millipore Corp., Bedford, MA) and sequencing was carried out using $A B I$ Prism BigDye Terminator Cycle Sequencing Ready Reaction Kits (Applied Biosystems, Foster City, CA) according to the manufacturer's instructions. Sequencing data was aligned and analyzed using the Vector $\left.N T\right|^{(\mathbb{R})}$ Suite (Informax, Bethesda, MD) and results were further validated in 340 unrelated Koreans by SNP genotyping as described below.

\section{Genotyping for the SNPs of the TGF- $\beta 1$ gene in the study population}

The two SNPs, at TGF- $\beta 1-509$ and in codon 10, the presence of which have been confirmed in this study were genotyped in 1,046 patients with chronic HBV infection and in 191 healthy controls by the single base extension (SBE) method. The PCR primer se- quences used for the amplification and extension of the TGF- $\beta 1$ SNPs by the SBE method are listed in Table 3. PCR was performed in a mixture of 1.25 pmol of each primer, $50 \mathrm{ng}$ of genomic DNA, 250 $\mu \mathrm{M}$ dNTPs and $0.15 \cup$ Taq DNA polymerase (Applied Biosystems) in the buffer provided by the manufacturer. Amplification was performed in a GeneAmp PCR System 9700 thermal cycler (Applied Biosystems). To clean up the PCR reaction for the primer extension reaction, one unit of shrimp alkaline phosphatase (SAP; Amersham Life Sciences, Cleveland, $\mathrm{OH})$ and two units of Exo I (Amersham Life Sciences) were added to the PCR products. The mixture was then incubated at $37^{\circ} \mathrm{C}$ for $1 \mathrm{~h}$, and at $72^{\circ} \mathrm{C}$ for 15 $\min$ to inactivate the enzymes.

Primer extension reactions were performed with a SNaPshot ddNTP Primer Extension Kit (Applied Biosystems) according to the manufacturer's instructions. To clean up the primer extension reaction, one unit of SAP was added to the reaction mixture, which was then incubated at $37^{\circ} \mathrm{C}$ for $1 \mathrm{~h}$, and then at $72^{\circ} \mathrm{C}$ for $15 \mathrm{~min}$ to inactivate the enzymes. The DNA samples, containing extension products, and Genescan $120 \mathrm{Liz}$ size standard solution (Applied Biosystems) were added to $\mathrm{Hi}$-Di formamide (Applied Biosystems) according to the manufacturer's instructions. The mixture was incubated at $95^{\circ} \mathrm{C}$ for $5 \mathrm{~min}$, and then placed on ice for $5 \mathrm{~min}$ and electrophoresed using an $A B \mid$ Prism 3100 Genetic Analyzer (Applied Biosystems). Results were analyzed using the $A B I$ Prism GeneScan and 
Genotyper (Applied Biosystems) software.

\section{Statistical analyses}

$\chi^{2}$ tests were used to compare the observed numbers of each genotype with those expected for the population using the Hardy-Weinberg equilibrium. Heterozygosity for each locus with allele frequencies $p$ and $q=1-p$ was calculated using $H=1-p^{2}-q^{2}=2 p(1-$ $p)$. We examined several widely used measures of linkage disequilibrium between all pairs of biallelic loci, namely, the value of the $\chi^{2}$ tests (corresponding $P$-values), Lewontin's $D^{\prime}\left(\left|D^{\prime}\right|\right)$ and the $d^{2}$ measure. Odds ratios with a 95\% confidence interval and $P$-values of the logistic regression models, controlling for the effects of age (as continuous variables) and sex, were computed using SAS for the analysis of categorized phenotypes based on the assumption that most patients, if not all, were infected with HBV perinatally (Stevens et al., 1975; Lok et al., 1987).

\section{Results}

\section{SNPs of the TGF- $\beta 1$ gene found in unrelated Korean individuals}

When polymorphisms were searched for in 24 unrelated Korean individuals by direct sequencing of the 7 exons and the promoter region of TGF- $\beta 1$ gene, only two known polymorphisms, $-509 \mathrm{C}>\mathrm{T}$ and $\mathrm{L} 10 \mathrm{P}$ $(29 \mathrm{~T}>\mathrm{C})$ were found at positions -509 in promoter region and codon 10 in exon 1 . No polymorphisms were found at positions $-988,-800,+72$, or at codon 25 or codon 263 in the 24 unrelated Korean individuals, and this was further confirmed by single base extension reactions and electrophoresis for the polymorphisms at positions -800 , codon 25 , and codon 263 in 340 unrelated Korean individuals. Consequently we tested TGF- $\beta 1-509$ and codon 10 polymorphisms in the present study.

\section{Genotype distribution}

The genotype distribution of TGF- $\beta 1-509$ and codon 10 polymorphisms were not significantly different between the control and patient groups (data not shown). The distributions of the genotypes of the polymorphisms at -509 and in codon 10 in patients with and without $\mathrm{HCC}$ are shown in Table 4. No evidence of a departure from the Hardy-Weinberg equilibrium was apparent. The genotype distribution of the TGF- $\beta 1$ -509 and codon 10 polymorphisms were significantly different in those with HCC and without HCC; the risk of $\mathrm{HCC}$ was significantly lower among patients with the $T / T$ or $C / T$ genotypes at position -509 than among patients with the $\mathrm{C} / \mathrm{C}$ genotype and was also lower among patients with the Pro/Pro or Leu/Pro genotypes in codon 10 than in those with the Leu/Leu genotype ( $P<0.02$ and $P<0.007$, respectively).

Haplotype analyses were performed and the possible four haplotype frequencies are shown in Table 5. Two major haplotypes account for more than $97 \%$ of these four haplotypes. TGF- $\beta 1-509 \mathrm{C}>\mathrm{T}$ and the L10P polymorphisms showed strong linkage disequilibrium $\left(\left|D^{\prime}\right|=0.985, d^{2}=0.919\right)$. By haplotype analysis, we found the possession of [-509T; L10P-Pro] conferred a decreased likelihood of $\mathrm{HCC}$ (OR $=0.74$; $95 \% \mathrm{Cl}, 0.59-0.93 ; P=0.008)$, while the [-509C; L10PLeu] haplotype was associated with an increased likelihood of $\mathrm{HCC}(\mathrm{OR}=1.37 ; 95 \% \mathrm{Cl}, 1.09-1.72 ; P$ $=0.006$ ) (Table 6).

Table 5. The Haplotype Frequencies in Korean patients with chronic HBV infection.

\begin{tabular}{cccc}
\hline Haplotypes & TGF- $\beta 1-509$ & $\begin{array}{c}\text { TGF- } \beta 1 \\
\text { codon } 10\end{array}$ & Frequencies \\
\hline 1 & C & Pro & 0.017 \\
2 & C & Leu & 0.537 \\
3 & T & Pro & 0.442 \\
4 & T & Leu & 0.003 \\
\hline
\end{tabular}

Table 4. Differential distribution of the TGF- $\beta 1$ genotypes in Korean patients with chronic HBV infection. Statistical analysis. Logistic regression models were used for calculating the odds ratios (95\% confidential interval) and corresponding P-values, controlling for age (continuous) and sex as covariates. Age was found to be highly associated with the occurrence of HCC $(P<0.0001)$ as expected. Sex was associated with the occurrence of HCC in patients with chronic HBV infection $(P<0.001)$.

\begin{tabular}{|c|c|c|c|c|c|}
\hline Loci & Genotype & With $\mathrm{HCC}$ & Without $\mathrm{HCC}$ & OR $(95 \% \quad \mathrm{Cl})$ & $P$ \\
\hline \multirow[t]{2}{*}{ TGF- $\beta 1 \quad-509$} & $\mathrm{C} / \mathrm{C}$ & $76(33.3 \%)$ & $187(24.2 \%)$ & - & \\
\hline & $\mathrm{C} / \mathrm{T}, \mathrm{T} / \mathrm{T}$ & $152(66.7 \%)$ & $586(75.8 \%)$ & $0.67(0.48-0.93)$ & 0.02 \\
\hline \multirow[t]{2}{*}{ TGF- $\beta 1$ codon 10} & Leu/Leu & $77(35.3 \%)$ & $183(24.4 \%)$ & - & \\
\hline & Leu/Pro, Pro/Pro & $141(64.7 \%)$ & $568(75.6 \%)$ & $0.62(0.45-0.88)$ & 0.007 \\
\hline
\end{tabular}


Table 6. Differential distribution of TGF- $\beta 1$ haplotypes in Korean patients with chronic HBV infection.

\begin{tabular}{lcccc}
\hline Haplotypes & With HCC $(2 n=416)$ & Without $\operatorname{HCC}(2 n=1,430)$ & OR $(95 \%$ Cl $)$ & $P$-values \\
\hline 1 [C; Pro] & 0.012 & 0.018 & $0.66(0.22-1.81)$ & 0.517 \\
2 [C; Leu] & 0.591 & 0.514 & $1.37(1.09-1.72)$ & 0.006 \\
3 [T; Pro] & 0.389 & 0.464 & $0.74(0.59-0.93)$ & 0.008 \\
4 [T; Leu] & 0.007 & 0.004 & $1.72(0.34-7.75)$ & 0.430 \\
\hline
\end{tabular}

\section{Discussion}

This study shows that among the 7 known SNPs of TGF- $\beta 1$ in the global populations, only two polymorphisms, at position -509 and in codon 10 were identified in the Korean population. No polymorphisms were found at positions $-988,-800,+72$, codon 25 , or codon 263. The presence of the TGF- $\beta 1-509 \mathrm{C}>\mathrm{T}$ or of the L10P polymorphism, and the combination of [-509C $>\mathrm{T} ; \mathrm{L}$ 10P] as a haplotype were found each to be strongly associated with a reduced risk of $\mathrm{HCC}$ occurrence in patients with chronic hepatitis B infection.

Previous studies in the Caucasian population have shown that the frequencies of the less frequent alleles at positions $-988,-800,+72$, codon 25 , and codon 263 are $0.002,0.088,0.078,0.082$ and 0.030 , respectively (Cambien et al., 1996). On the other hand, the frequencies at positions -509 and codon 10 were found to be 0.343 and 0.416 , respectively (Cambien et al., 1996). The allele frequencies of TGF- $\beta 1-509 T$ and Pro allele in codon 10 in Koreans were 0.48 and 0.47 respectively but uncommon polymorphisms were not found in this study in the Korean population. Differences in allele frequencies of polymorphisms of the TGF- $\beta 1$ gene in Caucasians and Koreans might be explained by ethnic difference. Lee et al. recently screened 300 SNPs selected from the public database in 24 Korean individuals and found that approximately $23 \%$ of the SNPs were not found (Lee et al., 2001). The results of the present study suggest that ethnic and population based differences should be considered in the selection of SNPS because highly frequent population-specific alleles are particularly useful for mapping the genes responsible for disease susceptibility and other traits in the population (Parra et al., 1998; Stephens et al., 2001). Further studies are needed to estimate the allele frequencies of these SNPs in other populations.

The -509 polymorphism is located in a potential regulatory region and recently it was found that the -509T allele is related to a higher plasma concentration of TGF- $\beta 1$ and a higher level of transcriptional activity than the $-509 \mathrm{C}$ allele (Grainger et al., 1999; Luedecking et al., 2000). A gene dose effect was observed for the $T$ allele; individuals homozygous for $-509 T / T$ had higher plasma concentrations of TGF- $\beta 1$ than heterozygous $\mathrm{C} / \mathrm{T}$ and homozygous $\mathrm{C} / \mathrm{C}$ individuals (Grainger et al., 1999). The Pro allele of the codon 10 polymorphism in the Japanese population was also found to be associated with higher serum levels of TGF- $\beta 1$ than the Leu allele (Yamada et al., 1998; Yokota et al., 2000). A gene dose effect was also found for the Pro allele (Yamada et al., 1998). These relationships might be expected by the strong linkage disequilibrium between the two polymorphisms of the TGF- $\beta 1$-509T promoter and Pro allele of the codon 10 , shown by this study $\left(\left|D^{\prime}\right|=0.985\right)$ and a study in the Caucasian population (|D'|=0.95) (Cambien et al., 1996). Therefore, polymorphisms which are associated with variations in the level of TGF- $\beta 1$ expression may alter susceptibility to cancer in humans (Tang et al., 1998). This hypothesis has been confirmed by a report that the Pro/Pro genotype in codon 10 of the TGF- $\beta 1$ gene is associated with a markedly reduced risk of breast cancer (Ziv et al., 2001). The present study shows that the possession of the $-509 T$ allele $(T / T$ or $C / T$ ) or of the Pro allele (Pro/Pro or Leu/Pro) in codon 10 is associated with a decreased risk of $\mathrm{HCC}$ as compared with patients having the $\mathrm{C}$ allele or the Leu allele only (C/C or Leu/Leu). The haplotype [-509C $>\mathrm{T} ; \mathrm{L} 10 \mathrm{P}]$ also showed a significant association with a reduced risk of HCC occurrence. TGF- $\beta 1-509 \mathrm{C} / \mathrm{T}$ genotype and Leu/Pro heterozygote genotype in codon 10 appear to be associated with a slightly higher level of TGF- $\beta 1$ than the $\mathrm{C} / \mathrm{C}$ or the Leu/Leu homozygote genotypes, respectively (Yamada et al., 1998; Grainger et al., 1999; Yokota et al., 2000). These findings might suggest that TGF$\beta 1$ induced suppression of HCC could be augmented by only a slight increase of the TGF- $\beta 1$ level by these genetic factors. These findings are consistent with the results of studies in transgenic mice and in hepatoma cell lines (Kim et al., 2002). Transgenic mice with a single TGF- $\beta 1$ gene deletion are more susceptible to liver and lung tumors induced by carcinogens (Tang et al., 1998), while the increased expression of TGF$\beta 1$ under the control of a murine mammary tumor virus promoter reduces the risk of induced mammary carcinoma (Pierce et al., 1995). In our study, the 
[-509C $>\mathrm{T}$; L10P] haplotype was found to be associated with a reduced risk of HCC with an odds ratio of 0.74 . These findings suggest that the TGF- $\beta 1$ polymorphism is one of the most important genetic factors in the control of HCC occurrence. These findings might be applied in clinical practice to stratify the risk groups for the occurrence of HCC in patients with chronic HBV infection. Further studies are needed to find polymorphisms in other genes that are more closely associated with HCC occurrence to be integrated into HCC surveillance programs in the future.

In conclusion, we found that the presence of the TGF- $\beta 1-509 C>T$ promoter or of the L10P polymorphism, and the combination $[-509 \mathrm{C}>\mathrm{T} ; \mathrm{L} 10 \mathrm{P}]$ as a haplotype was strongly associated with a reduced risk of HCC occurrence in patients with chronic HBV infection. This finding might be useful in clinical practice in the design of HCC surveillance programs in patients with chronic HBV infection, if further genetic susceptibilities are identified.

\section{Acknowledgment}

This work was supported by the $21 \mathrm{C}$ Frontier Functional Human Genome Project (grant number FG-416) operated under the auspices of the Korean Ministry of Science and Technology.

\section{References}

Awad MR, El-Gamel A, Hasleton P, Turner DM, Sinnott PJ, Hutchinson IV. Genotypic variation in the transforming growth factor-beta1 gene: association with transforming growth factorbeta1 production, fibrotic lung disease, and graft fibrosis after lung transplantation. Transplantation 1998;66:1014-20

Bruix J, Sherman M, Llovet JM, Beaugrand M, Lencioni R, Burroughs AK, Christensen E, Pagliaro L, Colombo M, Rodes J. Clinical management of hepatocellular carcinoma. Conclusions of the Barcelona-2000 EASL conference. European Association for the Study of the Liver. J Hepatol 2001;35:421-30

Cambien F, Ricard S, Troesch A, Mallet C, Generenaz L, Evans A, Arveiler D, Luc G, Ruidavets JB, Poirier O. Polymorphisms of the transforming growth factor-beta 1 gene in relation to myocardial infarction and blood pressure. The Etude Cas-Temoin de I'Infarctus du Myocarde (ECTIM) Study. Hypertension 1996;28:881-7

Cui W, Fowlis DJ, Bryson S, Duffie E, Ireland $H$, Balmain A, Akhurst RJ. TGFbeta1 inhibits the formation of benign skin tumors, but enhances progression to invasive spindle carcinomas in transgenic mice. Cell 1996;86:531-42

Dickinson JA, Wun YT, Wong SL. Modelling death rates for carriers of hepatitis B. Epidemiol Infect 2002;128:83-92

El-Gamel A, Awad MR, Hasleton PS, Yonan NA, Hutchinson JA, Campbell CS, Rahman AH, Deiraniya AK, Sinnott PJ,
Hutchinson IV. Transforming growth factor-beta (TGF-beta1) genotype and lung allograft fibrosis. J Heart Lung Transplant 1999;18:517-23

Grainger DJ, Heathcote K, Chiano M, Snieder H, Kemp PR, Metcalfe JC, Carter ND, Spector TD. Genetic control of the circulating concentration of transforming growth factor type beta1. Hum Mol Genet 1999;8:93-7

Kim BC, Mamura M, Choi KS, Calabretta B, Kim SJ. Transforming growth factor beta 1 induces apoptosis through cleavage of $\mathrm{BAD}$ in a Smad3-dependent mechanism in $\mathrm{FaO}$ hepatoma cells. Mol Cell Biol 2002;22:1369-78

Lee SG, Hong S, Yoon Y, Yang I, Song K. Characterization of publicly available SNPS in the Korean population. Hum Mutat 2001;17:281-4

Lok AS, Lai CL, Wu PC, Wong VC, Yeoh EK, Lin HJ. Hepatitis $B$ virus infection in Chinese families in Hong Kong. Am J Epidemiol 1987;126:492-9

Luedecking EK, DeKosky ST, Mehdi H, Ganguli M, Kamboh Ml. Analysis of genetic polymorphisms in the transforming growth factor-beta1 gene and the risk of Alzheimer's disease. Hum Genet 2000;106:565-9

Parra EJ, Marcini A, Akey J, Martinson J, Batzer MA, Cooper $\mathrm{R}$, Forrester T, Allison DB, Deka R, Ferrell RE, Shriver MD. Estimating African American admixture proportions by use of population-specific alleles. Am J Hum Genet 1998;63:183951

Pasche B, Kolachana P, Nafa K, Satagopan J, Chen YG, Lo RS, Brener D, Yang D, Kirstein L, Oddoux C, Ostrer H, Vineis $P$, Varesco $L$, Jhanwar $S$, Luzzatto $L$, Massague $J$, Offit K. TbetaR-I (6A) is a candidate tumor susceptibility allele. Cancer Res 1999;59:5678-82

Pierce DF Jr, Gorska AE, Chytil A, Meise KS, Page DL, Coffey RJ Jr, Moses HL. Mammary tumor suppression by transforming growth factor beta 1 transgene expression. Proc Natl Acad Sci USA 1995;92:4254-8

Purcell RH. The discovery of the hepatitis viruses. Gastroenterology 1993;104:955-63

Stephens JC, Schneider JA, Tanguay DA, Choi J, Acharya T, Stanley SE, Jiang R, Messer CJ, Chew A, Han JH, Duan J, Carr JL, Lee MS, Koshy B, Kumar AM, Zhang G, Newell WR, Windemuth A, Xu C, Kalbfleisch TS, Shaner SL, Arnold K, Schulz V, Drysdale CM, Nandabalan K, Judson RS, Ruano G, Vovis GF. Haplotype variation and linkage disequilibrium in 313 human genes. Science 2001;293:489-93

Stevens CE, Beasley RP, Tsui J, Lee WC. Vertical transmission of hepatitis B antigen in Taiwan. N Engl J Med 1975; 292:771-4

Tang B, Bottinger EP, Jakowlew SB, Bagnall KM, Mariano $\mathrm{J}$, Anver MR, Letterio JJ, Wakefield LM. Transforming growth factor-beta1 is a new form of tumor suppressor with true haploid insufficiency. Nat Med 1998;4:802-7

Wollenberg GK, Semple E, Quinn BA, Hayes MA. Inhibition of proliferation of normal, preneoplastic, and neoplastic rat hepatocytes by transforming growth factor-beta. Cancer Res 1987; 47:6595-9

Yamada Y, Miyauchi A, Goto J, Takagi Y, Okuizumi H, Kanematsu M, Hase M, Takai H, Harada A, Ikeda K. As- 
sociation of a polymorphism of the transforming growth factor-beta1 gene with genetic susceptibility to osteoporosis in postmenopausal Japanese women. J Bone Miner Res 1998; 13:1569-76

Yokota M, Ichihara S, Lin TL, Nakashima N, Yamada Y. Association of a T29 $\rightarrow \mathrm{C}$ polymorphism of the transforming growth factor-beta1 gene with genetic susceptibility to myocardial infarction in Japanese. Circulation 2000;101:2783-7

Yu MC, Yuan JM, Govindarajan S, Ross RK. Epidemiology of hepatocellular carcinoma. Can J Gastroenterol 2000;14: 703-9
Yu MW, Chang HC, Liaw YF, Lin SM, Lee SD, Liu CJ, Chen $\mathrm{PJ}$, Hsiao TJ, Lee $\mathrm{PH}$, Chen CJ. Familial risk of hepatocellular carcinoma among chronic hepatitis B carriers and their relatives. J Natl Cancer Inst 2000;92:1159-64

Ziv E, Cauley J, Morin PA, Saiz R, Browner WS. Association between the $T 29 \rightarrow C$ polymorphism in the transforming growth factor beta1 gene and breast cancer among elderly white women: The study of osteoporotic fractures. JAMA 2001;285:2859-63 